\title{
Seção Livre
}




\title{
Os diferentes raciocínios matemáticos
}

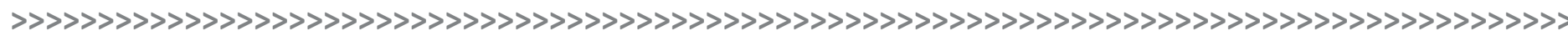

Luiz Davi Mazzei ${ }^{1}$

\section{Resumo:}

Este texto procura, através da apresentação e análise de exemplos, promover um debate filosófico sobre dois tipos de raciocínio presentes na matemática: o raciocínio demonstrativo e o raciocínio probabilístico. O objetivo deste texto é auxiliar na compreensão dessas duas formas de raciocínio e como são ambas importantes no âmbito da matemática. Para tanto utilizarei como principal referência teórica a nomenclatura proposta Marcelo Dascal sobre formas de racionalidade, quais sejam: a racionalidade hard e a racionalidade soft. Raciocínios construídos no âmbito da racionalidade hard são raciocínios demonstrativos, que buscam a prova e a certeza. Raciocínios construídos no escopo da racionalidade soft são raciocínios probabilísticos, que buscam a 'chance' de ocorrência (ou não) de determinada situação. A partir dessa diferenciação, apresento maneiras pelas quais essas racionalidades dialogam entre si no interior da matemática.

\section{Palavras-chave:}

Racionalidade. Matemática. Probabilidade.

\begin{abstract}
:
This paper aims to analyze, through the use of Mathematical examples, two types of rationality and how they interact and complement each other. We use the naming proposed by Marcelo Dascal regarding the forms of rationality, as theoretical reference. According to Dascal, there are two forms of rationality: the 'hard' rationality, corresponding to the traditional concept of rationality, and the 'soft' rationality, taking into account of what are provable and concrete. Based on this difference, we propose to analyze how these rationalities interact. It will be presented Mathematical examples that support the argument in favor of the dialog between both rationalities.
\end{abstract}

\section{Keywords:}

Rationality. Mathematics. Probability.

O conceito de racionalidade científica, como tradicionalmente é entendido, está bastante próximo da visão aristotélica expressa em Analíticos Anteriores (ARISTÓTELES, 2010) e entende por racionalidade científica o raciocínio demonstrativo, construído a partir de premissas que expressam verdades básicas e necessárias. A racionalidade da Ciência, na visão tradicional, busca a prova, a verdade. Utilizando a denominação proposta por Marcelo Dascal (2006, p. 324): "Por racionalidade hard entendo una concepção de racio- 
nalidade que tem a lógica clássica e suas aplicações como modelo fundamental”. Esse tipo de racionalidade tem a certeza como seu principal objetivo e os limites entre o certo e o errado estão bem definidos. Essa forma de racionalidade, que muitas vezes é aceita como única, é a racionalidade da matemática, a qual é, dito de maneira sintética, um sistema baseado em deduções lógicas, a partir de alguns axiomas, provendo explicações universalmente válidas. Ou seja, apresenta princípios e regras que sejam válidas em todas as situações análogas à analisada. No dizer de Dascal:

Tal concepção considera como condições da práxis e do pensamento racional, ou como suas manifestações preferidas, parâmetros como: a obediência irrestrita ao princípio de contradição, a utilização de definições precisas formuladas em termos de condições necessárias e suficientes; a argumentação visando a conclusões irrefutáveis, modelada sobre a dedução. (DASCAL, 2006, p. 325)

A Matemática é aqui referida como exemplo de racionalidade hard, uma vez que está baseada em um sistema lógico-demonstrativo, com uma simbologia própria que transcende as barreiras linguísticas e com validade universal. Na Matemática é possível estabelecer com certeza o valor de verdade de uma proposição. Expressando a realidade através de símbolos matemáticos, fica claro e evidente se algo é verdadeiro ou falso, certo ou errado. Dessa forma, a Matemática ganha o status de 'linguagem privilegiada' da Ciência. Além disso, as provas obtidas através de demonstrações matemáticas são incontestáveis, pois apresentam os nexos necessários, estão inseridas em um sistema de axiomas e são logicamente deduzidas a partir destes.

Entretanto, há outro tipo de racionalidade, uma racionalidade que dá conta de tudo aquilo que é possível, provável, mas não necessariamente verdadeiro. É a racionalidade soft, mantendo a mesma nomenclatura dada por Dascal:

Por racionalidade soft entendo, em um sentido mais amplo, uma concepção de racionalidade que procura levar em conta e desenvolver os meios para lidar com um grande número de situações - tanto teóricas como práticas - em que a incerteza e a imprecisão são a regra. (DASCAL, 2006, p. 325)

Esse tipo de racionalidade permite uma ampliação no debate sobre a realidade, pois cobre uma grande gama de aspectos que eram descartados pela racionalidade hard como irracionais. Todavia, enquanto a racionalidade hard define claramente o "racional" e atribui ao "irracional" aquilo que não se abriga sob o que entende ser "racional" a racionalidade soft opera no âmbito do possível, do razoável, que se encontra entre o certo e o errado. Em uma oposição, a racionalidade hard vê apenas um dos lados como correto, verdadeiro, enquanto que a racionalidade soft aceita a possibilidade de ambos os lados estarem corretos, ou parcialmente corretos. A argumentação baseada na racionalidade hard busca sempre a escolha de uma posição certa, descartando as demais. Por outro lado, uma argumentação baseada na racionalidade soft, não busca a determinação de uma posição correta, mas permite uma análise abrangente da situação, aceitar uma posição, conciliar todas ou escolher alternativas diferentes das apresentadas até então.

Esse tipo de raciocínio nos fornece não uma decisão pronta e "certa", mas uma base racional para que tomemos uma decisão. Além disto, nessa análise a influência do contexto no peso das razões - que é impossível quantificar com precisão - é levada em consideração, ao invés de descartada como algo irracional. Valendo-se da expressão de Leibniz, Dascal (2012, p. 67) diz que, na racionalidade soft, a balança da razão inclina sem necessitar. 
Proponho alguns exemplos da Matemática que serão analisados a partir da perspectiva da existência das duas formas de racionalidades. Primeiro, vamos analisar algumas situações na qual os alunos empregam raciocínio demonstrativo, que são raciocínios construídos no âmbito da racionalidade hard. Na Matemática, há diversas formas de demonstração, dentre as quais a demonstração algébrica e a demonstração geométrica, que iremos apresentar nesse texto. Vamos a um exemplo de demonstração geométrica:

Partimos do princípio de que a área (S) de um retângulo é calculada pelo produto da base (b) pela altura (h).

\section{Figura 1}

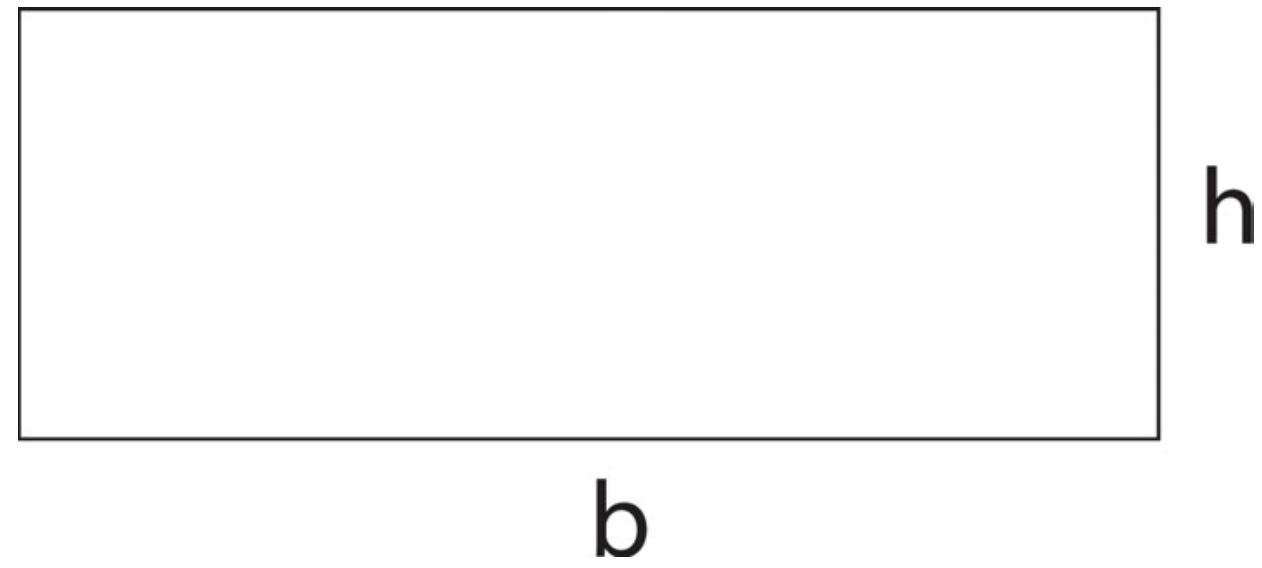

Assim: S=b.h

A partir de então vamos demonstrar a fórmula que permite calcular a área de um triângulo qualquer. A partir de um dos vértices da base do retângulo traça-se um segmento de reta até um ponto qualquer do lado oposto a este vértice. Faz-se o mesmo a partir do outro vértice, de forma que os dois segmentos se encontrem no mesmo ponto, traçando assim, um triângulo. A seguir, traçamos a altura deste triângulo (que tem a mesma medida da altura do retângulo).

Figura 2

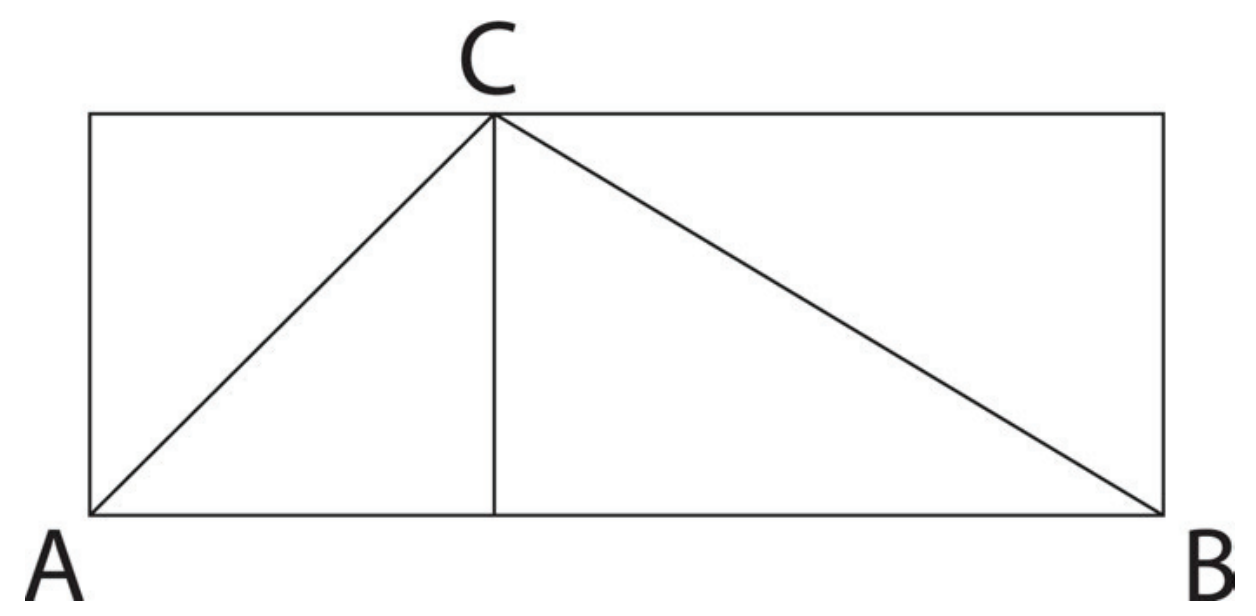

Podemos observar que temos agora dois quadriláteros distintos, cada um dividido em duas partes congruentes por um dos lados do triângulo. 
Figura 3

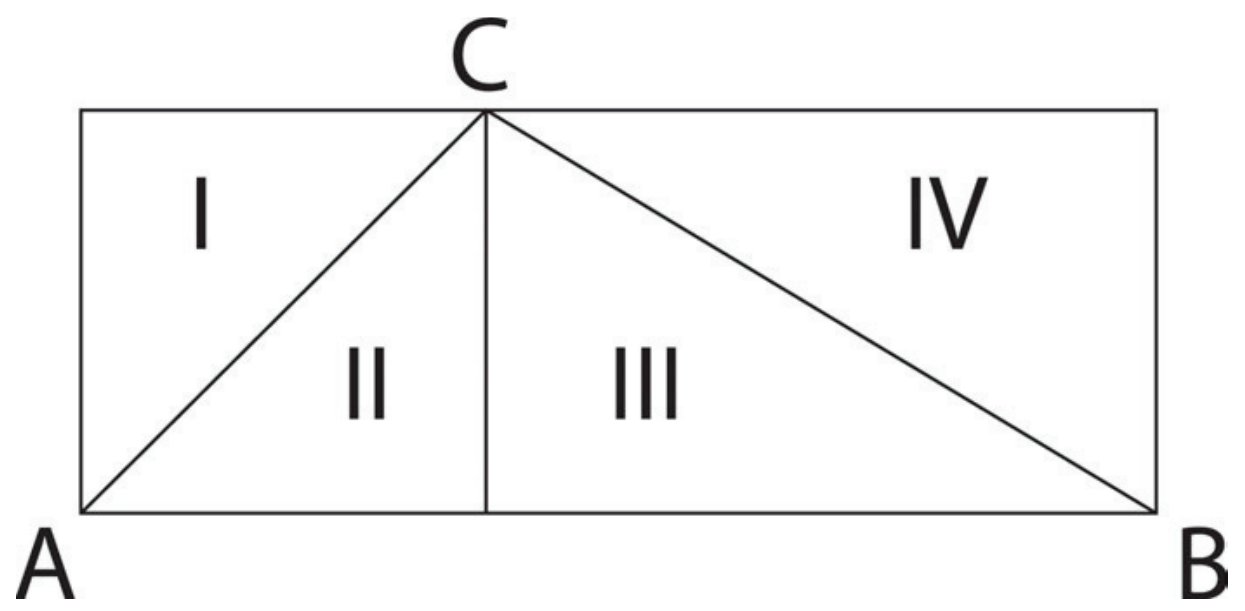

Os triângulos I e II são congruentes, assim como os triângulos III e IV. Isso significa que a área do triângulo $\mathrm{ABC}$ é a metade da área do retângulo. Ou seja, a área (S) de um triângulo qualquer é

Essa demonstração, que prova a validade da fórmula acima para calcular a área de um triângulo, utilizou o princípio silogístico, que diz: se as premissas forem verdadeiras, a conclusão será necessariamente verdadeira, por força das relações lógicas existentes entre as premissas. Nesse caso, partiu-se de premissas aceitas como verdadeiras, estabeleceram-se relações entre estas e chegou-se a uma conclusão que é logicamente verdadeira e sobre a qual não cabe discussão. Utilizaram-se premissas universais, que se aplicam a quaisquer retângulos, e chegou-se a uma conclusão também universal, qual seja, a fórmula para calcular a área de qualquer triângulo.

Outra forma de demonstração matemática que também segue os mesmos princípios é a demonstração algébrica. Vamos demonstrar algebricamente, partir de uma representação geométrica, o teorema de Pitágoras.

Analisando a figura abaixo podemos observar que um quadrado construído sobre a hipotenusa de um triângulo retângulo é quatro vezes a área deste triângulo mais a área do quadrado restante, cujo lado mede (b-a).

\section{Figura 4}
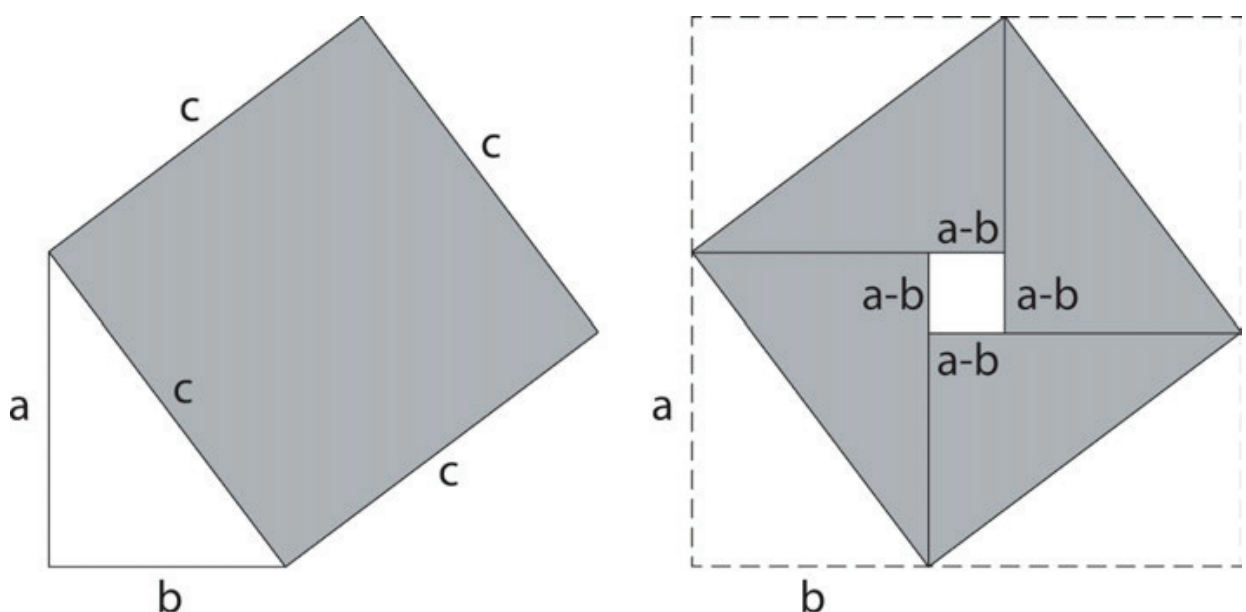

b

Assim:

$\mathrm{C}^{2}=4 .(\mathrm{a} \cdot \mathrm{b}) / 2+(\mathrm{a}-\mathrm{b})^{2}$

Logo teremos:

$C^{2}=2 \cdot a \cdot b+a^{2}-2 \cdot a \cdot b+b^{2}$ (pelo desenvolvimento do produto notável $\left.(a-b)^{2}\right)$

Assim, temos:

$C^{2}=a^{2}+b^{2}$ 
Essa demonstração do teorema de Pitágoras também preenche os mesmos requisitos: parte de premissas verdadeiras e através de operações lógicas leva a uma conclusão também verdadeira. Esses exemplos mostram o porquê de a Matemática ser considerada por boa parte dos filósofos da Ciência como um perfeito exemplo de racionalidade hard. Esses exemplos não deixam margem para dúvidas ou questionamentos. Suas conclusões, obtidas logicamente a partir de premissas universais, são também universais, aplicáveis a toda a classe de triângulos, não apenas aos apresentados. São esses raciocínios que os alunos usualmente reconhecem como matemática.

Resta apresentar exemplos da Matemática que estejam ligados à racionalidade soft. Essa racionalidade que trabalha com a imprecisão, a incerteza, tem lugar na Matemática, ainda que essa seja considerada um perfeito exemplo de racionalidade hard? Certamente, especialmente na Teoria das Probabilidades. Embora sua estrutura esteja sujeita às normas e seja obtida através da demonstração, com valor universal, quando a aplicamos aos particulares, estabelecemos bases para tomada de decisão entre dois juízos, ou duas opções. Ao tratarmos de problemas que envolvem o cálculo da probabilidade de que determinado evento singular ocorra (ou não), utilizamos a Matemática, com sua estrutura hard, mas vamos obter respostas que estão no âmbito do opinável, do possível. Os resultados obtidos podem ser tais como os resultados obtidos por outros raciocínios matemáticos, classificados em certos ou errados. Entretanto, os resultados obtidos a partir dessa forma de raciocínio não garantem certeza (exceto em casos nos quais a probabilidade de ocorrência é de 100\% ou zero) quando vistos no contexto.

O estudo das probabilidades está bastante ligado à racionalidade $s o f t$, pois em uma argumentação baseada nesse tipo de racionalidade, buscamos o convencimento, a persuasão, a inclinação, e para isso o cálculo das probabilidades pode ser decisivo. Essa parte trata do possível, mas não determina o que irá ou não ocorrer. Estabelece o que é mais (ou menos) provável. Esse raciocínio serve de base para a argumentação baseada na racionalidade soft, pois nos dá pistas e indícios de quão provável é a ocorrência de um determinado evento.

Usaremos uma discussão sobre um tema qualquer como exemplo: uma pessoa afirma que num jogo de 'cara ou coroa', com uma moeda honesta, ganhou 12 vezes sucessivas, sempre apostando 'cara'. Essa afirmação é verdadeira ou falsa? Vamos examinar: tal fato é possível? Matematicamente, sim, embora a probabilidade desse resultado não seja muito alta. Dada a improbabilidade deste resultado, espera-se que ocorra apenas uma vez a cada 4096 tentativas. Mas não há como ter certeza nem de que a moeda seja ou não honesta, nem de que a pessoa diga ou não a verdade. Ficamos inclinados a não acreditar nessa pessoa, ainda que seja impossível assegurar que ela esteja mentindo.

Outro exemplo interessante de se analisar é o exame de DNA. Se na análise do DNA recolhida na cena de um crime indica que a amostra recolhida pertence ao suspeito, com 99,9999\% de certeza, tal argumento se mostra bastante convincente aos jurados. Esse argumento é, muitas vezes, capaz de convencer e servir como guia para a tomada de decisão, muito embora ele não seja conclusivo. Analisando a informação apresentada, qual seja, uma probabilidade de 99,9999\% significa que existe uma chance de erro a cada 1.000 .000 de amostras. Num país como o Brasil, no qual a população é próxima de 290 milhões de habitantes, há possivelmente 290 indivíduos que apresentarão o mesmo resultado. Assim, embora o cálculo apresentado sirva como um guia para decisão, não traz a certeza, nem prova a verdade de fato algum.

Esses exemplos buscam mostrar que raciocínio matemático vai além do raciocínio demonstrativo, que tem na certeza seu principal objetivo. A matemática tão citada como exemplo de racionalidade hard, também proporciona uma base para a construção de argumentos que serão empregados em debates e tomadas de decisões baseadas na racionalidade soft. Nem todo o argumento matemático logicamente construído e perfeitamente 
verdadeiro serve para provar sem sombra de dúvidas o valor de verdade de uma proposição, quando aplicado a explicações de casos singulares. Com essas ponderações, queremos mostrar que a matemática permite a construção de argumentos racionais, tanto do tipo hard quanto do tipo soft. Esses dois tipos não são incompatíveis, mas complementares. Para Dascal (2012, p. 118) [...] "diferentes tipos de racionalidad no sólo coexisten, sino que también no se excluyen entre si ni reducen la aceptabilidad o inteligibilidad del o a la conformidad con sus propios criterios." Queremos, assim, enfatizar a importância de abordar a matemática não somente a partir de raciocínios demonstrativos, que produzem respostas verdadeiras e sobre as quais não cabem dúvidas, mas também a partir de raciocínios probabilísticos que indicam a 'chance' de determinados eventos ocorrer ou não. Ambos os raciocínios servem de guia para tomada de decisão: o raciocínio do tipo hard indica qual a posição é correta e, portanto, deve ser necessariamente aceita, enquanto que o raciocínio soft indica qual posição é mais provável, mas não implica na necessidade de sua aceitação. A matemática, assim entendida, ultrapassa o status de 'ciência exata' e ganha importância no cotidiano dos alunos como instrumento capaz de produzir argumentos racionais que tanto podem provar a verdade ou falsidade de uma proposição quanto podem convencer (ou orientar) quanto à tomada de uma decisão. O estudo da probabilidade no ensino médio é uma excelente oportunidade para que o professor explore as diferentes maneiras de raciocínio e promova uma discussão junto aos alunos sobre os significados dos resultados. O cálculo de probabilidade oferece ao professor a possibilidade de empregar o cálculo matemático como um guia para tomada de decisão. Os Parâmetros Curriculares Nacionais - PCN (Brasil, 1997) estabelecem que a principal finalidade para o estudo de probabilidade é a de que:

O aluno compreenda que grande parte dos acontecimentos do cotidiano são de natureza aleatória e é possível identificar prováveis resultados desses acontecimentos. As noções de acaso e incerteza, que se manifestam intuitivamente, podem ser exploradas na escola, em situações nas quais o aluno realiza experimentos e observa eventos (Brasil, 1997, p. 56).

A racionalidade soft, que subjaz a interpretação dos resultados particulares obtidos em um cálculo de probabilidade, não se opõe à necessidade da racionalidade hard que dá o suporte aos algoritmos empregados no cálculo. Esse é um argumento que indica a complementaridade das duas formas de racionalidade. Cabe ao professor proporcionar espaços nos quais os alunos construam argumentos matemáticos tanto do tipo hard, que são aplicados a um número restrito de situações, quanto do tipo soft, que estão presentes no cotidiano de todos nós.

\section{Referências}

ARISTÓTELES. Órganon. 5. ed. São Paulo: Edipro, 2010.

BRASIL. Secretaria de Educação Fundamental. Parâmetros curriculares nacionais: matemática. Brasília, DF: MEC/SEF, 1997. 126 p.

DASCAL, Marcelo. O auto-debate é possível? Dissolvendo alguns de seus supostos paradoxos. Manuscrito, Campinas, v. 29, n. 2, p. 319-349, jul./dez. 2006.

. Leibniz y el dialogo entre racionalidades. In: NUDLER, Oscar; FIERRO, María Angélica; SATNE, Glenda. La Filosofía a través del espejo. 1. ed. Buenos Aires: Miño y Dávila, 2012. 